\title{
Existence and uniqueness results for best proximity points
}

\author{
Moosa Gabeleh
}




\title{
EXISTENCE AND UNIQUENESS RESULTS FOR BEST PROXIMITY POINTS
}

\author{
MOOSA GABELEH \\ Received 24 September, 2013
}

\begin{abstract}
Let us consider a non-self mapping $T: A \rightarrow B$, where A and $\mathrm{B}$ are two nonempty subsets of a metric space $(X, d)$. The aim of this paper is to solve the nonlinear programming problem that consists in minimizing the real valued function $x \longmapsto d(x, T x)$, where $T$ belongs to a new class of non-self mappings. In especial case, existence and uniqueness of fixed point for Kannan type self mappings are also obtained.
\end{abstract}

2010 Mathematics Subject Classification: 47H10; 47H09

Keywords: best proximity point, fixed point, proximal Kannan non-self mapping

\section{INTRODUCTION}

Let $A$ and $B$ be two nonempty subsets of a metric space $X$. A non-self mapping $T: A \rightarrow B$ is said to be a contraction if there exists a constant $r \in[0,1)$, such that $d(T x, T y) \leq r d(x, y)$, for all $x, y \in A$. The well-known Banach contraction principle states that if $A$ is a complete subset of $X$ and $T$ is a contraction self-mapping, then the fixed point equation $T x=x$ has exactly one solution.

The Banach contraction principle is a very important tools in nonlinear analysis and there are many extensions of this principle; see, e.g., [13] and the references therein.

Let $(X, d)$ be a metric space. A self-mapping $T: X \rightarrow X$ is called Kannan mapping if there exists $\alpha \in\left[0, \frac{1}{2}\right)$ such that

$$
d(T x, T y) \leq \alpha[d(x, T x)+d(y, T y)],
$$

for all $x, y \in X$. We know that if $X$ is complete metric space, every Kannan selfmapping defined on $X$ has a unique fixed point ([12]). Note that, the notion of contraction mappings and Kannan mappings are independent. That is, there exists a contraction mapping, which is not Kannan and a Kannan mapping, which is not a contraction. Therefore, we cannot compare these two class of mappings directly.

Recently, Kikkawa and Suzuki in [14], established the following fixed point theorem, which is an extension of Kannan's fixed point theorem. 
Theorem 1 ([14]). Define a non-increasing function $\varphi$ from $[0,1)$ into $\left(\frac{1}{2}, 1\right]$ by

$$
\varphi(r)=\left\{\begin{array}{l}
1 \quad \text { if } \quad 0 \leq r<\frac{1}{\sqrt{2}}, \\
\frac{1}{1+r} \quad \text { if } \quad \frac{1}{\sqrt{2}} \leq r<1 .
\end{array}\right.
$$

Let $(X, d)$ be a complete metric space and let $T$ be a self-mapping on $X$. Let $\alpha \in$ $\left[0, \frac{1}{2}\right)$ and put $r:=\frac{\alpha}{1-\alpha} \in[0,1)$. Assume that

$$
\varphi(r) d(x, T x) \leq d(x, y) \quad \text { implies } \quad d(T x, T y) \leq \alpha[d(x, T x)+d(y, T y)],
$$

for all $x, y \in X$. Then $T$ has a unique fixed point $z$ and $\lim _{n} T^{n} x=z$ holds for every $x \in X$.

It is interesting to note that the function $\varphi(r)$ defined in Theorem 1 is the best constant for every $r$ (see Theorem 2.4 of [14]).

\section{PReliminaries}

Consider the non-self mapping $T: A \rightarrow X$, in which $A$ is a nonempty subset of a metric space $(X, d)$. Clearly, the fixed point equation $T x=x$ may not have solution. Hence, it is contemplated to find an approximate $x \in A$ such that the error $d(x, T x)$ is minimum. Indeed, best approximation theory has been derived from this idea. Here, we state the following well-known best approximation theorem due to Kay Fan.

Theorem 2 ([8]). Let A be a nonempty compact convex subset of a normed linear space $X$ and $T: A \rightarrow X$ be a continuous mapping. Then there exists $x \in A$ such that $\|x-T x\|=\operatorname{dist}(T x, A):=\inf \{\|T x-a\|: a \in A\}$.

A point $x \in A$ in the above theorem is called a best approximant point of $T$ in $A$. The notion of best proximity point for non-self mappings is introduced in a similar fashion:

Definition 1. Let $A$ and $B$ be nonempty subsets of a metric space $(X, d)$ and $T: A \rightarrow B$ be a non-self mapping. A point $p \in A$ is called a best proximity point of $T$ if

$$
d(p, T p)=\operatorname{dist}(A, B):=\{d(x, y):(x, y) \in A \times B\} .
$$

In fact, best proximity point theorems have been studied to find necessary conditions such that the minimization problem

$$
\min _{x \in A} d(x, T x),
$$

has at least one solution.

Best proximity point theory is an interesting topic in optimization theory which recently attracted the attention of many authors (see for instance [1-9,16]).

Let $A$ and $B$ be two nonempty subsets of a metric space $(X, d)$. Let us fix the following notations which will be needed throughout this article:

$$
A_{0}:=\{x \in A: d(x, y)=\operatorname{dist}(A, B) \text { for some } y \in B\},
$$




$$
B_{0}:=\{y \in B: d(x, y)=\operatorname{dist}(A, B) \text { for some } \quad x \in A\} .
$$

It is easy to see that if $(A, B)$ is a nonempty and weakly compact pair of subsets of a Banach space $X$, then $\left(A_{0}, B_{0}\right)$ is also nonempty pair $X$.

The notion of proximal contractions was defined by Sadiq Basha, as follows.

Definition 2 ([15]). Let $(A, B)$ be a pair of nonempty subsets of a metric space $(X, d)$. A mapping $T: A \rightarrow B$ is said to be a proximal contraction if there exists a non-negative real number $\alpha<1$ such that, for all $u_{1}, u_{2}, x_{1}, x_{2} \in A$,

$$
\left\{\begin{array}{l}
d\left(u_{1}, T x_{1}\right)=\operatorname{dist}(A, B) \\
d\left(u_{2}, T x_{2}\right)=\operatorname{dist}(A, B)
\end{array} \quad \Rightarrow d\left(u_{1}, u_{2}\right) \leq \alpha d\left(x_{1}, x_{2}\right) .\right.
$$

Definition 3 ([15]). Let $A, B$ be two nonempty subsets of a metric space $(X, d)$. $A$ is said to be approximatively compact with respect to $B$ if every sequence $\left\{x_{n}\right\}$ of $A$ satisfying the condition that $d\left(y, x_{n}\right) \rightarrow D(y, A)$ for some $y \in B$ has a convergent subsequence.

Next theorem is the main result of [15].

Theorem 3. Let $(A, B)$ be a pair of nonempty closed subsets of a complete metric space $(X, d)$ such that $A_{0}$ is nonempty and $B$ is approximatively compact with respect to $A$. Assume that $T: A \rightarrow B$ is a proximal contraction such that $T\left(A_{0}\right) \subseteq B_{0}$. Then $T$ has a unique best proximity point.

We mention that in [10], the current author extended Theorem 3 and established a best proximity point theorem under weaker conditions with respect to Theorem 3 , due to Sadiq Basha (see Theorem 2.1 and Corollary 2.1 of [10]).

In this article, we introduce a new class of mappings called weak proximal Kannan non-self mappings and obtain a similar result of Theorem 1 for this new class of nonself mappings.

\section{MAIN RESULTS}

To establish our main results, we introduce the following new class of non-self mappings.

Definition 4. Define a strictly decreasing function $\theta$ from $\left[0, \frac{1}{2}\right)$ onto $\left(\frac{1}{2}, 1\right]$ by

$$
\theta(r)=1-r .
$$

Let $(A, B)$ be a nonempty pair of subsets of a metric space $(X, d)$. Let $\alpha \in\left[0, \frac{1}{2}\right)$ and put $r:=\frac{\alpha}{1-\alpha}$. Then $T: A \rightarrow B$ is said to be a weak proximal Kannan non-self mapping if for all $u, v, x, y \in A$ with

$$
d(u, T x)=\operatorname{dist}(A, B) \& d(v, T y)=\operatorname{dist}(A, B),
$$

we have

$$
\theta(r) d^{*}(x, T x) \leq d(x, y) \text { implies } d(u, v) \leq \alpha\left[d^{*}(x, T x)+d^{*}(y, T y)\right] .
$$


The notion of proximal Kannan non-self mapping can be defined as below.

Definition 5. Let $(A, B)$ be a nonempty pair of subsets of a metric space $(X, d)$. Then $T: A \rightarrow B$ is said to be a proximal Kannan non-self mapping if there exists $\alpha \in\left[0, \frac{1}{2}\right)$ such that for all $u, v, x, y \in A$ with

$$
d(u, T x)=\operatorname{dist}(A, B) \& d(v, T y)=\operatorname{dist}(A, B),
$$

we have

$$
d(u, v) \leq \alpha\left[d^{*}(x, T x)+d^{*}(y, T y)\right] .
$$

It is clear that the class of weak proximal Kannan non-self mappings contains the class of proximal Kannan non-self mappings as a subclass. Also, the class of proximal Kannan non-self mappings contains the class of Kannan non-self mappings.

We now state our main result of this article.

Theorem 4. Let $(A, B)$ be a nonempty pair of subsets of a complete metric space $(X, d)$ such that $A_{0}$ is nonempty and closed. Assume that $T: A \rightarrow B$ is a weak proximal Kannan non-self mapping such that $T\left(A_{0}\right) \subseteq B_{0}$. Then there exists a unique point $x^{*} \in A$ such that $d\left(x^{*}, T x^{*}\right)=\operatorname{dist}(A, B)$. Moreover, if $\left\{x_{n}\right\}$ is a sequence in $A$ such that $d\left(x_{n+1}, T x_{n}\right)=\operatorname{dist}(A, B)$, then $x_{n} \rightarrow x^{*}$.

Proof. Assume $x_{0} \in A_{0}$. Since $T\left(A_{0}\right) \subseteq B_{0}$, there exists $x_{1} \in A_{0}$ such that $d\left(x_{1}, T x_{0}\right)=\operatorname{dist}(A, B)$. Again, since $T x_{1} \in B_{0}$, there exists $x_{2} \in A_{0}$ such that $d\left(x_{2}, T x_{1}\right)=\operatorname{dist}(A, B)$. Continuing this process, we can find a sequence $\left\{x_{n}\right\}$ in $A_{0}$ such that

$$
d\left(x_{n+1}, T x_{n}\right)=\operatorname{dist}(A, B), \text { for all } n \in \mathbb{N} \cup\{0\} .
$$

Thus,

$$
d\left(x_{0}, T x_{0}\right) \leq d\left(x_{0}, x_{1}\right)+d\left(x_{1}, T x_{0}\right)=d\left(x_{0}, x_{1}\right)+\operatorname{dist}(A, B),
$$

and so,

$$
\theta(r) d^{*}\left(x_{0}, T x_{0}\right) \leq d^{*}\left(x_{0}, T x_{0}\right) \leq d\left(x_{0}, x_{1}\right) \quad \& \quad\left\{\begin{array}{l}
d\left(x_{1}, T x_{0}\right)=\operatorname{dist}(A, B), \\
d\left(x_{2}, T x_{1}\right)=\operatorname{dist}(A, B) .
\end{array}\right.
$$

Since $T$ is a weak proximal Kannan non-self mapping, we conclude that

$$
\begin{aligned}
d\left(x_{1}, x_{2}\right) & \leq \alpha\left[d^{*}\left(x_{0}, T x_{0}\right)+d^{*}\left(x_{1}, T x_{1}\right)\right] \\
& \leq \alpha\left[d\left(x_{0}, x_{1}\right)+d^{*}\left(x_{1}, T x_{0}\right)+d\left(x_{1}, x_{2}\right)+d^{*}\left(x_{2}, T x_{1}\right)\right] \\
& =\alpha\left[d\left(x_{0}, x_{1}\right)+d\left(x_{1}, x_{2}\right)\right] .
\end{aligned}
$$

Therefore,

$$
d\left(x_{1}, x_{2}\right) \leq \frac{\alpha}{1-\alpha} d\left(x_{0}, x_{1}\right)=r d\left(x_{0}, x_{1}\right) .
$$


Similarly, we can see that

$$
\theta(r) d^{*}\left(x_{1}, T x_{1}\right) \leq d\left(x_{1}, x_{2}\right) \quad \& \quad\left\{\begin{array}{l}
d\left(x_{2}, T x_{1}\right)=\operatorname{dist}(A, B), \\
d\left(x_{3}, T x_{2}\right)=\operatorname{dist}(A, B) .
\end{array}\right.
$$

This implies that

$$
\begin{aligned}
d\left(x_{2}, x_{3}\right) & \leq \alpha\left[d^{*}\left(x_{1}, T x_{1}\right)+d^{*}\left(x_{2}, T x_{2}\right)\right] \\
& \leq \alpha\left[d\left(x_{1}, x_{2}\right)+d^{*}\left(x_{2}, T x_{1}\right)+d\left(x_{2}, x_{3}\right)+d^{*}\left(x_{3}, T x_{2}\right)\right] \\
& =\alpha\left[d\left(x_{1}, x_{2}\right)+d\left(x_{2}, x_{3}\right)\right] .
\end{aligned}
$$

So,

$$
d\left(x_{2}, x_{3}\right) \leq \frac{\alpha}{1-\alpha} d\left(x_{1}, x_{2}\right)=r d\left(x_{1}, x_{2}\right) \leq r^{2} d\left(x_{0}, x_{1}\right) .
$$

Hence, by induction, we conclude that

$$
d\left(x_{n}, x_{n+1}\right) \leq r^{n} d\left(x_{0}, x_{1}\right),
$$

which implies that

$$
\Sigma_{n=1}^{\infty} d\left(x_{n}, x_{n+1}\right) \leq \Sigma_{n=1}^{\infty} r^{n} d\left(x_{0}, x_{1}\right)<\infty .
$$

That is, $\left\{x_{n}\right\}$ is a Cauchy sequence in $A_{0}$. Since $A_{0}$ is closed and $X$ is complete metric space, we deduce that $\left\{x_{n}\right\}$ is a convergent sequence. Let $x^{*} \in A_{0}$ be such that $x_{n} \rightarrow x^{*}$. We claim that $x^{*}$ is a unique best proximity point of $T$. At first, we prove that

$$
d^{*}\left(x^{*}, T x\right) \leq \alpha d\left(x^{*}, x\right), \quad \forall x \in A_{0} \quad \text { with } \quad x \neq x^{*} .
$$

Let $x \in A_{0}$ and $x \neq x^{*}$. Since $T\left(A_{0}\right) \subseteq B_{0}$, there exists $y \in A_{0}$ such that $d(y, T x)=$ $\operatorname{dist}(A, B)$. By the fact that $x_{n} \rightarrow x^{*}$, there exists $N_{1} \in \mathbb{N}$ such that

$$
d\left(x_{n}, x^{*}\right) \leq \frac{1}{3} d\left(x, x^{*}\right), \quad \forall n \geq N_{1} .
$$

We now have

$$
\begin{aligned}
\theta(r) d^{*}\left(x_{n}, T x_{n}\right) & \leq d^{*}\left(x_{n}, T x_{n}\right)=d\left(x_{n}, T x_{n}\right)-\operatorname{dist}(A, B) \\
& \leq d\left(x_{n}, x^{*}\right)+d\left(x^{*}, x_{n+1}\right)+d\left(x_{n+1}, T x_{n}\right)-\operatorname{dist}(A, B) \\
& =d\left(x_{n}, x^{*}\right)+d\left(x^{*}, x_{n+1}\right) \leq \frac{2}{3} d\left(x, x^{*}\right) \\
& =d\left(x, x^{*}\right)-\frac{1}{3} d\left(x, x^{*}\right) \leq d\left(x, x^{*}\right)-d\left(x_{n}, x^{*}\right) \\
& \leq d\left(x_{n}, x\right) .
\end{aligned}
$$

Thus,

$$
\theta(r) d^{*}\left(x_{n}, T x_{n}\right) \leq d\left(x_{n}, x\right) \quad \& \quad\left\{\begin{array}{l}
d\left(x_{n+1}, T x_{n}\right)=\operatorname{dist}(A, B), \\
d(y, T x)=\operatorname{dist}(A, B) .
\end{array}\right.
$$


Again, since $T$ is weak proximal Kannan non-self mapping we conclude that

$$
d\left(x_{n+1}, y\right) \leq \alpha\left[d^{*}\left(x_{n}, T x_{n}\right)+d^{*}(x, T x)\right] \leq \alpha\left[d\left(x_{n}, x_{n+1}\right)+d^{*}(x, T x)\right] .
$$

Thereby,

$$
\begin{aligned}
d\left(x^{*}, T x\right) & =\lim _{n \rightarrow \infty} d\left(x_{n}, T x\right) \\
& \leq \lim _{n \rightarrow \infty}\left[d\left(x_{n}, x_{n+1}\right)+d\left(x_{n+1}, y\right)+d(y, T x)\right] \\
& \leq \lim _{n \rightarrow \infty}\left[(1+\alpha) d\left(x_{n}, x_{n+1}\right)+\alpha d^{*}(x, T x)+d(y, T x)\right] \\
& \leq \lim _{n \rightarrow \infty}\left[(1+\alpha) r^{n} d\left(x_{0}, x_{1}\right)+\alpha d^{*}(x, T x)+\operatorname{dist}(A, B)\right] \\
& =\alpha d^{*}(x, T x)+\operatorname{dist}(A, B) .
\end{aligned}
$$

Then,

$$
d^{*}\left(x^{*}, T x\right) \leq \alpha d^{*}(x, T x), \quad \forall x \in A_{0}, \quad \text { with } \quad x \neq x^{*} .
$$

That is, (3.3) holds. It now follows from (3.3) that

$$
\begin{aligned}
d^{*}\left(x_{n}, T x_{n}\right) & \leq d\left(x_{n}, x^{*}\right)+d^{*}\left(x^{*}, T x_{n}\right) \\
& \leq d\left(x_{n}, x^{*}\right)+\alpha d^{*}\left(x_{n}, T x_{n}\right) .
\end{aligned}
$$

Thus,

$$
\theta(r) d^{*}\left(x_{n}, T x_{n}\right)=(1-r) d^{*}\left(x_{n}, T x_{n}\right) \leq(1-\alpha) d^{*}\left(x_{n}, T x_{n}\right) \leq d\left(x_{n}, x^{*}\right) .
$$

On the other hand, since $x^{*} \in A_{0}$ and $T\left(A_{0}\right) \subseteq B_{0}$, there exists $y^{*} \in B_{0}$ such that $d\left(y^{*}, T x^{*}\right)=\operatorname{dist}(A, B)$. Therefore,

$$
\theta(r) d^{*}\left(x_{n}, T x_{n}\right) \leq d\left(x_{n}, x^{*}\right) \quad \& \quad\left\{\begin{array}{l}
d\left(x_{n+1}, T x_{n}\right)=\operatorname{dist}(A, B), \\
d\left(y^{*}, T x^{*}\right)=\operatorname{dist}(A, B),
\end{array}\right.
$$

which implies that

$$
\begin{aligned}
d\left(x_{n+1}, y^{*}\right) & \leq \alpha\left[d^{*}\left(x_{n}, T x_{n}\right)+d^{*}\left(x^{*}, T x^{*}\right)\right] \\
& \leq \alpha\left[d\left(x_{n}, x_{n+1}\right)+d^{*}\left(x_{n+1}, T x_{n}\right)+d^{*}\left(x^{*}, T x^{*}\right)\right] .
\end{aligned}
$$

If in above relation $n \rightarrow \infty$, we obtain

$$
\begin{aligned}
d\left(y^{*}, x^{*}\right) & \leq \alpha d^{*}\left(x^{*}, T x^{*}\right) \\
& =\alpha\left[d\left(x^{*}, y^{*}\right)+d^{*}\left(y^{*}, T x^{*}\right)\right]=\alpha d\left(x^{*}, y^{*}\right) .
\end{aligned}
$$

This deduces that $d\left(x^{*}, y^{*}\right)=0$ or $x^{*}=y^{*}$. Hence $x^{*}$ is a best proximity point of the mapping $T$. The uniqueness of best proximity point follows from the condition that $T$ is weak proximal Kannan non-self mapping. That is, suppose that $x_{1}^{*}, x_{2}^{*}$ are two distinct points in $A$ such that $d\left(x_{i}^{*}, T x_{i}^{*}\right)=\operatorname{dist}(A, B)$, for $i=1,2$. So,

$$
\theta(r) d^{*}\left(x_{1}^{*}, T x_{1}^{*}\right) \leq d\left(x_{1}^{*}, x_{2}^{*}\right) \quad \& \quad\left\{\begin{array}{l}
d\left(x_{1}^{*}, T x_{1}^{*}\right)=\operatorname{dist}(A, B), \\
d\left(x_{2}^{*}, T x_{2}^{*}\right)=\operatorname{dist}(A, B),
\end{array}\right.
$$


Then,

$$
0<d\left(x_{1}^{*}, x_{2}^{*}\right) \leq \alpha\left[d^{*}\left(x_{1}^{*}, T x_{1}^{*}\right)+d^{*}\left(x_{2}^{*}, T x_{2}^{*}\right)\right]=0,
$$

which is a contradiction. Hence, the best proximity point is unique.

The following corollaries are obtained from Theorem 4.

Corollary 1. Let $(A, B)$ be a nonempty pair of subsets of a complete metric space $(X, d)$ such that $A_{0}$ is nonempty and closed. Assume that $T: A \rightarrow B$ is a proximal Kannan non-self mapping such that $T\left(A_{0}\right) \subseteq B_{0}$. Then there exists a unique point $x^{*} \in A$ such that $d\left(x^{*}, T x^{*}\right)=\operatorname{dist}(A, B)$. Moreover, if $\left\{x_{n}\right\}$ is a sequence in $A$ such that $d\left(x_{n+1}, T x_{n}\right)=\operatorname{dist}(A, B)$ then, $x_{n} \rightarrow x^{*}$.

Corollary 2. Let $(A, B)$ be a nonempty pair of a complete metric space $(X, d)$ such that $A_{0}$ is nonempty and closed. Assume that $T: A \rightarrow B$ is a Kannan nonself mapping such that $T\left(A_{0}\right) \subseteq B_{0}$. Then there exists a unique point $x^{*} \in A$ such that $d\left(x^{*}, T x^{*}\right)=\operatorname{dist}(A, B)$. Moreover, if $\left\{x_{n}\right\}$ is a sequence in $A$ such that $d\left(x_{n+1}, T x_{n}\right)=\operatorname{dist}(A, B)$ then, $x_{n} \rightarrow x^{*}$.

Corollary 3. Let $A$ be a nonempty and closed subset of a complete metric space $(X, d)$. Assume that $T: A \rightarrow A$ is a self mapping such that

$$
\theta(r) d(x, T x) \leq d(x, y) \text { implies } d(T x, T y) \leq \alpha[d(x, T x)+d(y, T y)],
$$

for all $x, y \in A$, where $\theta(r)$ is defined as in the Definition 4. Then T has a unique fixed point $x^{*} \in A$. Moreover, if $x_{0} \in A$ and we define $x_{n+1}=T x_{n}$, then $x_{n} \rightarrow x^{*}$.

Corollary 4 (Kannan fixed point theorem). Let $A$ be a nonempty and closed subset of a complete metric space $(X, d)$. Assume that $T: A \rightarrow A$ is a Kannan mapping. Then $T$ has a unique fixed point. Moreover, for each $x_{0} \in A$ if we define $x_{n+1}=T x_{n}$ then the sequence $\left\{x_{n}\right\}$ converges to the fixed point of $T$.

Example 1. Suppose that $X=\mathbb{R}$ with the usual metric. Suppose that

$$
A:=[0,2] \cup\{5\} \quad \& \quad B:=[3,4] .
$$

Then $A$ and $B$ are nonempty closed subsets of $X$ and $A_{0}=\{2,5\}$ and $B_{0}=\{3,4\}$. Note that $\operatorname{dist}(A, B)=1$. Let $T: A \rightarrow B$ be a mapping defined as

$$
T(x)=\left\{\begin{array}{lll}
\frac{7}{2} & \text { if } & x=0 \\
4 & \text { if } & x \neq 0
\end{array}\right.
$$

It is easy to see that $T$ is weak proximal Kannan non-self mapping for each $\alpha \in$ $\left[0, \frac{1}{2}\right)$. Indeed, it is sufficient to note that $d(u, T x)=\operatorname{dist}(A, B)$, holds for $u=5$ and $x \in A-\{0\}$. Therefore, Theorem 4 guaranties the existence and uniqueness of a best proximity point for $T$ and this point is $x^{*}=5$. 
Example 2. Suppose that $X=\mathbb{R}$ with the usual metric. Suppose that

$$
A:=\left[0, \frac{1}{100}\right] \cup\{1\} \quad \& \quad B:=[2,3] .
$$

Then $A$ and $B$ are nonempty closed subsets of $X$ and $\operatorname{dist}(A, B)=1$. Define a non-self mapping $T: A \rightarrow B$ as follows

$$
T(x)=\left\{\begin{array}{l}
2 \text { if } \quad x \in \mathbb{Q} \cap A, \\
\frac{101}{50} \text { if } \quad x \in \mathbb{Q}^{c} \cap A .
\end{array}\right.
$$

Note that $T$ is not continuous. We claim that $T$ is Kannan nons-elf mapping with $\alpha=\frac{1}{3}$. For this purpose, it is sufficient to consider two following cases.

Case 1. If $x \in \mathbb{Q} \cap A-\{1\}$ and $y \in \mathbb{Q}^{c} \cap A$, then

$$
\alpha\left[d^{*}(x, T x)+d^{*}(y, T y)\right]=\frac{1}{3}\left[\frac{101}{50}-(x+y)\right] \geq \frac{2}{3}>\frac{1}{50}=d(T x, T y) .
$$

Case 2. If $x=1$ and $y \in \mathbb{Q}^{c} \cap A$, then

$$
\alpha\left[d^{*}(x, T x)+d^{*}(y, T y)\right]=\frac{1}{3}\left[\frac{51}{50}-y\right] \geq \frac{1}{3} \times \frac{101}{100}>\frac{1}{50}=d(T x, T y) .
$$

It now follows from Corollary 2 that $T$ has a unique best proximity point and this point is $x^{*}=1$.

Remark 1. We mention that in [11] the author studied the existence of best proximity points in metric spaces with a partial order, where weak proximal Kannan non-self mappings are satisfied only for comparable elements.

\section{REFERENCES}

[1] A. Abkar and M. Gabeleh, "Best proximity points for asymptotic cyclic contraction mappings," Nonlin. Anal., vol. 74, no. 18, pp. 7261-7268, 2011.

[2] A. Abkar and M. Gabeleh, "Proximal quasi-normal structure and a best proximity point theorem," J. Nonlin. Convex Anal., vol. 44, no. 4, pp. 653-659, 2013.

[3] M. Al-Thagafi and N. Shahzad, "Convergence and existence results for best proximity points," Nonlin. Anal., vol. 70, no. 10, pp. 3665-3671, 2009.

[4] A. Amini Harandi, "Best proximity point theorems for cyclic strongly quasi-contraction mappings," J. Glob. Optim., vol. 56, no. 4, pp. 1667-1674, 2013.

[5] C. Di Bari, T. Suzuki, and C. Vetro, "Best proximity points for cyclic Meir- Keeler contractions," Nonlin. Anal., vol. 69, no. 11, pp. 3790-3794, 2008.

[6] A. Eldred and P. Veeramani, "Existence and convergence of best proximity points," J. Math. Anal. Appl., vol. 323, no. 2, pp. 1001-1006, 2006.

[7] R. Espinola, "A new approach to relativelt nonexpansive mappings," Proc. Amer. Math. Soc., vol. 136, no. 6, pp. 1987-1996, 2008.

[8] K. Fan, "Extensions of two fixed point theorems of F.E. Browder," Math. Z., vol. 122, no. 3, pp. 234-240, 1969. 
[9] M. Gabeleh, "Proximal weakly contractive and proximal nonexpansive non-self mappings in metric and Banach spaces," J. Optim. Theory Appl., vol. 158, no. 2, pp. 615-625, 2013.

[10] M. Gabeleh, "Best proximity points for weak proximal contractions," Bull. Malaysian Math. Sci. Soc., in press.

[11] M. Gabeleh, "Discrete optimization for ordered weak proximal Kannan contractions," Analele Stiint Ifice Ale Universitat II "AL.I. Cuza" Din Iasi (S.N.), to appear.

[12] R. Kannan, "Some results on fixed points," Amer. Math. Monthly, vol. 76, no. 4, pp. 405-408, 1969.

[13] M. Khamsi and W. Kirk, An introduction to metric spaces and fixed point theory, 2nd ed., ser. Series is books. New York: Wiley-Interscience, 2001, vol. III.

[14] M. Kikkawa and T. Suzuki, "Some similarity between contractions and Kannan mappings," Fixed Point Theory Appl., vol. 2008, pp. 1-8, 2010.

[15] S. Sadiq Basha, "Best proximity points: optimal solutions," J. Optim. Theory Appl., vol. 151, no. 1, pp. 210-216, 2011.

[16] W. Sanhan, C. Mongkolkeha, and P. Kumam, "Generalized proximal $\psi$ - contraction mappings and best proximity points," Abstract Appl. Anal., vol. 2012, pp. 1-19, 2012.

Author's address

Moosa Gabeleh

Department of Mathematics, Ayatollah Boroujerdi University, Boroujerd, Iran

E-mail address: gab.moo@gmail.com, Gabeleh@abru.ac.ir 